\title{
A Study of Knowledge \& Awareness of Medical Doctors Towards Radiation Exposure Risk At Tikur Anbessa Specialized Referral And Teaching Hospital, Addis Ababa, Ethiopia.
}

\author{
Daniel Zewdneh ${ }^{1}$, Seife Teferi Dellie ${ }^{2}$, Tewodros Ayele ${ }^{3}$ \\ ${ }^{1,2,3}$ Department of Radiology, College of Health Sciences / Addis Ababa University, Ethiopia,
}

\begin{abstract}
Increasing concern has recently been expressed in the literature that the referring doctor's knowledge of radiation doses incurred during radiological procedures is inadequate. Such information may be particularly relevant when the expansion of imaging technology is considered. Hence the objective of this work is to assess the awareness of physicians about radiation dose and hazards of radiation. The study was performed among medical doctors at Tikur Anbessa Specialized Referral Teaching Hospital, the largest medical school in the country. A 135 self administered questionnaire was circulated randomly from a range of specialties; out of which 114 questionnaires were completed and used in the study giving a response rate of 85\%. Participants were asked about the radiation dose from a chest radiograph, the annual dose from background radiation, and cancer risk from several common radiological procedures. A mean score of 7.1 out of 19 was achieved. 12 doctors had received formal training about ionizing radiation, and these participants scored higher than those with no previous training in this area. Our survey suggested that clinicians' awareness of radiation doses imparted during common radiological procedures, and the consequent risk to the individual patient is poor. A major curriculum revision of both undergraduate and graduate medical education regarding awareness on radiation is mandatory to improve this deficiency.
\end{abstract}

Keywords: Radiation exposure, radiation dose, lifetime cancer risk, radiation protection

\section{Introduction}

Everyone alive in this world is constantly being exposed to ionizing radiation and about $18 \%$ exposure is due to man-made source $[1,2]$. There is likely to be a risk to patients' health in investigations that involve ionizing radiation. The US National Council on Radiation Protection and Measurement had reported that medical x-rays and nuclear medicine account for only $15 \%$ of all radiation exposures [1,2]. Similarly, in the UK, estimated 100-250 deaths occur each year from cancers directly related to medical exposure to radiation [1, 2]. More concern has recently been aired in recent studies that the knowledge of referring doctors about radiation doses incurred during diagnostic radiological procedures is deficient [1-4]. Such information may be of particular relevance when the expansion of imaging technology is considered. The advent of multi detector row CT (MDCT) has allowed for faster imaging and the use of more complex imaging protocols. In turn, this has led to a rise in the number of $\mathrm{CT}$ examinations performed per annum and consequently in the amount of radiation to which patients are exposed [5, 6]. A survey from one large American institution in 2002 estimated that CT may account for only $15 \%$ of the procedures performed in a radiology department, yet it is responsible for up to $75 \%$ of the medically administered radiation dose to the population [7]. Contemporary studies from the UK [8,9] and Norway [10], in 2004 and 2007, respectively, quoted figures of 47\% and 59\% for the collective medical radiation dose to the population from CT examinations.

In children, the lifetime cancer risks resulting from exposure to radiation are higher than those in the adult population [11]. A British survey in 1989 showed that 4\% of all CT examinations were performed on children younger than 15 years of age [12]. However by 1999, this figure had risen to $11.2 \%$ [13].

In addition, investigators continue to express concern that $\mathrm{CT}$ parameters are not always adjusted to take into account the age and varying sizes of pediatric patients $[14,15]$, with children frequently being imaged using adult CT protocols $[14,16]$, thus exposing them to an unnecessarily high radiation dose as a consequence. Previously published surveys in the literature have illustrated that radiation dose is not an important consideration for clinicians when they refer their patients for diagnostic radiological examinations [17] and that, when asked, they tend to underestimate the radiation dose that patients receive [18, 22].

With regard to the situation in Ethiopia, there was no information available on the subject. There is no study done on the issue so far to our knowledge. With these facts in mind, we undertook a survey of medical doctors working in Tikur Anbessa Specialized Teaching Hospital (TASH) to evaluate their knowledge of the radiation doses their patients receive during some of the more common radiological procedures requested. 
Study design and settings

\section{Methods}

A cross-sectional study was conducted between the dates of 02/09/2009-15/12/2009G.C among sampled health professional in Tikur Anbessa Specialized Hospital (TASH) who use radiologic investigations in their day to day medical practice.

The target population was all qualified health medical doctors (i.e Interns, GPs, Residents and consultants) who are working in TASH.

\section{Sample size \& sampling}

There were 76 medical interns, 5 GPs, 97 consultants and 234 residents in the various departments of the medical faculty of AAU making the study population. Systematic random sampling method was employed taking the physician in each department as a study unit. All the physicians in each department who were on duty during the study period were given serial numbers. One out of three physicians was sampled by systematic random sampling technique to obtain a sample size of 135 physicians using the formula $\mathrm{N} / \mathrm{k}=\mathrm{n}$ where $\mathrm{N}$ is the target population and $\mathrm{k}$ is every third interval and $\mathrm{n}$ the assumed sample size.

\section{Data collection procedure}

Data were collected using anonymous, well structured pretested self administered questionnaires in multiple choice formats, with responders ticking the correct answer for each question from a choice of possible answers. Questionnaires were distributed to each of the doctors selected and returned within a week of submission.

\section{Variables and Coding-}

Various variables like socio-demographic data, field of specialty and specific questions to determine knowledge of background radiation exposure, the dose and risks of various radiologic procedures to which a patient is exposed during various radiologic investigative modalities at TASH were included in the questionnaire. Finally, the doctors were asked if they knew the lifetime risk of inducing a fatal cancer from the same list of examinations. Knowledge about radiation was assessed using questions. Some of the questions used include: 1 . How much radiation does a patient absorb during chest $\mathrm{x}$-rays? With response categories indicating different doses. 2. Do you think that x-ray can cause abnormality? With response categories as yes, no, and do not know.3. Do you advise patients and your colleagues to limit the use of x-rays? With response categories coded as yes or no. Correct responses were scored as having one point and wrong responses, do not know or blank responses were given no point or " 0 " making a total of 19 points. Mean scores of the scored points were then analyzed

\section{Data analysis procedure}

The data were entered into SPSS version 15.0 software and the results were analyzed. Distribution of variables was assessed using descriptive statistics. In addition, parametric tests were performed to examine differences between physician groups in their responses to knowledge and awareness questions.

\section{Ethical consideration:}

Information sheet explaining about the objectives of the study and the benefit of the research findings to patients undergoing radiologic investigation in particular and advancement of medical science in general was provided to each study subject before submitting the questionnaire. A brief consent form was also submitted to the study participants and those who consented were provided with the self administered questionnaire. Data collection was anonymous and the investigators did not provide any individual information to a third party.

The proposal was submitted to the Institutional Review Board (IRB) of the medical faculty for ethical clearance

\section{Results}

Among the 135 questionnaires distributed 114 were filled and collected. The age of the respondents ranged from 21 to 50yrs. Among the respondents 19 were female \& 95 male.

A total of 114 questionnaires were returned giving a response rate of $85 \%$. The responding doctors included 18 consultants, 61 residents, 33 medical interns \& 2 GPs (Table1).

Concerning the specialty of the respondents 12 were from radiology, 15 from Internal medicine, 14 from Surgery, 10 from Gynecology/Obstetrics, 9 from Pediatrics, 1 from Orthopedics, 18 were Consultants, \& 35 had no Specialty (i.e. Interns \& GPs) (Table 2).

Thirty out of 114 doctors $(26 \%)$ achieved a score of 9 or more marks out of 19 . The mean score achieved was 7.1 out of 19 , and the median score was 8.0. The mean score for consultants was 7.3, whereas the mean score for those formal training was 14.2. No respondent gave correct answers to all of the questions asked. 
Only 21 doctors (18.4\%) correctly identified the effective dose of a chest radiograph (Table-3). Thirtytwo (32) $(28.1 \%)$ correctly identified how the effective dose of a chest radiograph compared to the annual dose received from background radiation (Table 4).

Six respondents $(5.3 \%)$ were incorrect in their assumption that ultrasound examinations involved the use of ionizing radiation, whereas 8 (7.1\%) mistakenly thought that an MR study of the brain (with contrast) used ionizing radiation. 33.3\% did not know about radiation dose and risk associated with it (Table-5), and 3 doctors mistakenly thought an MRI of the brain with iv contrast utilized more radiation than the dose they estimated for an unenhanced MRI of the brain while $31.6 \%$ had no idea.

The lifetime risk of inducing a fatal cancer from an abdominal CT examination is estimated to be 1 in 2000 for an adult patient [22]; however, only 10 doctors (8.8\%) appeared to be aware of this association. Seventeen doctors (14.9\%) erroneously replied that a CT scan of the abdomen had a lifetime risk of inducing a fatal carcinoma of less than 1 in a million (Table-6).

Twelve doctors $(10.5 \%)$ had received some kind of formal training about ionizing radiation. None of the twelve doctors achieved a score of less than 13 out of 19. Statistical analysis of these data showed that the difference in the distribution of scores between those having formal training and those without training is significant, with the distribution of scores showing that training led to a greater proportion of higher scores. Doctors who had received formal training in ionizing radiation appeared to recognize, for example, that an abdominal X-ray examination involved significantly more radiation than a chest radiograph, with 7 out of 12 (58.3\%) responding that the dose was 10-50 times that of a chest radiograph, compared with 19 out of 102 $(18.6 \%)$ in the "no formal training" group .

\section{Discussion}

Various studies had documented deficiencies in knowledge among medical students, doctors, paramedics and dentists about their understanding of ionizing radiation or the use of equipment involved in the process [19-22]. Our survey also shows that clinicians' awareness of the radiation doses imparted during common diagnostic imaging procedures, and the consequent risks to the individual patient, is poor .It demonstrated that those who have had formal training about ionizing radiation have a greater awareness of the risks involved, compared with those who have had no training. Furthermore, it showed (as one would perhaps hope) that residents in radiology were more familiar than their clinical colleagues from other specialties about radiation doses and risks. This may of course simply reflect that radiologists have ready access to the appropriate information, as well as the training that they have received about ionizing radiation, which could assist in answering the questions.

The deficiency in knowledge of a medical doctors might alter the expected benefits compared to the risk involved, and can affect medical decisions. Therefore, this study emphasizes the need for all health providers to equip themselves with current and appropriate information about ionizing and non-ionizing radiation. Along with providing objective facts, they must also address the emotional needs of patients. Appropriate educational efforts combined with effective communication skills resolve errors in judgment that are linked to inadequate or inaccurate information. Explaining implications of radiation should be considered as vital by every health professional, along with efforts to maximize basic radiation protection. Healthcare providers should basically understand the basic physics, chemistry and biology of radiation in order to effectively impart and communicate facts about it as well as promote and practice appropriate protection measures. An adequate response should be given to any question raised by patients. Moreover, an effective medical education model should be developed in medical schools and health training institutions to address the knowledge gap currently seen in clinical practice.

Patient education about radiation should be part of the responsibility of healthcare providers. This study concludes that the majority of medical doctors at Tikur Anbessa Specialized Teaching Hospital have a very limited knowledge regarding radiation source, risk and essential protection. Misconceptions about exposure and risk were also observed in the medical community of the hospital. One can hardly refrain from extrapolating that the problem affects the wider healthcare provider community nationwide in view of the fact that the teaching hospital is the source of most of the professionals practicing in the country. It is identified that a major curriculum revision of both undergraduate and graduate medical education regarding awareness on radiation is mandatory to improve this deficiency.

This study has limitations in terms of generalization from a limited sample size. We have not stratified samples into categories to see the differences in the level of knowledge among categories of physicians.

\section{Recommendation}

There is a need to re-educate clinicians about (i) ionizing radiation relevant to medical imaging, and (ii) their clinical role to provide accurate information to their patients, and (iii) the potential hazards associated, as well as (iv) The proper execution of protective measures. (v)Medical education curricula may need revisiting regarding the safe use and hazards of radiation. (vi) Further studies on a larger scale, with the inclusion of 
A Study of Knowledge \& Awareness of Medical Doctors towards Radiation Exposure Risk at Tikur attitude and practice components, involving both healthcare providers and consumers may be required for more solid information on the issue.

\section{References:}

[1] Radman.co.uk.RadmanAssociates;2007.Availablefrom:http://www.radman.co.uk/training/RPSCourses.pdf [Accessed10 June 2008].

[2] Bury B. X-ray dose training: are we exposed to enough. Clin Radiol 2004;59:926.

[3] Jacob K, Vivian G, Steel JR. X-ray dose training: are we exposed to enough? Clin Radiol 2004;59:928-34.

[4] Gower-Thomas K, Lewis MH, Shiralkar S, Snow M, Galland RB, Rennie A. Doctor's knowledge of radiation exposures is deficient. Br Med J 2002;324:919.

[5] Adams D. Blast from the past: a cautionary tale. Br Med J 2002;324:121.

[6] Brix G, Nagel HD, Stamm G, Veit R, Lechel U, Griebel J, et al. Radiation exposure in multi-slice versus single slice spiral CT: results of a nationwide survey. Eur Radiolgy 2003;13:1979-91.

[7] Yates SJ, Pike LC, Goldstone KE. Effect of multislice scanners on patient dose from routine CT examinations in East Anglia. Br J Radiol 2004;77:472-8

[8] Wiest PW, Locken JA, Heintz PH, Mettler FA Jr. CT scanning: a major source of radiation exposure. Semin Ultrasound CT MR 2002;23:402-10.

[9] Shrimpton PC, Hillier MC, Lewis MA, Dunn M. National survey of doses from CT in the UK: 2003. Br J Radiol 2006;79:968-80.

[10] Hart D, Wall BF. UK population dose from medical X-ray examinations. Eur J Radiol 2004;50:285-91.

[11] Borretzen I, Lysdahl KB, Olerud HM. Diagnostic radiology in Norway: trends in examination frequency and collective effective dose. Radiat Prot Dosimetry 2007;124: 339-47

[12] Brenner DJ, Elliston CD, Hall EJ, Berdon WE. Estimated risks of radiation-induced fatal cancer from paediatric CT. Am J Roentgenol 2001;176:289-96.

[13] Shrimpton PC, Edyvean S. CT scanner dosimetry. Br JRadiol 1998;71:1-3.

[14] Mettler FA Jr, Wiest PW, Locken JA, Kelsey CA. CT scanning: patterns of use and dose. J Radiol Prot 2000;20:353-9.

[15] Paterson A, Frush DP, Donnelly LF. Helical CT of the body: are settings adjusted for pediatric patients? Am J Roentgenol 2001;176:297-301

[16] Hollingsworth C, Frush DP, Cross M, Lucaya J. Helical CT of the body: a survey of the techniques used for pediatric patients. AJR Am J Roentgenol 2003;180:401-6.

[17] Rogers LF. Taking care of children: check out the parameters used for helical CT. AJR Am J Roentgenol 2001;176:287.

[18] Scatarige JC, Diette GB, Haponik EF, Merriman B, Fishman EK. Availability, requesting practices, and barriers to referral for highresolution CT of the lungs: results of a survey of U.S. pulmonologists. Acad Radiol 2002;9:1370-7.

[19] Shiralkar S, Rennie A, Snow M, Galland RB, Lewis MH, Gower-Thomas K. Doctor's knowledge of radiation exposure: questionnaire study. Br Med J 2003;327:371-2.

[20] Finestone A, Schlesinger T, Amir H, Richter E, Milgrom C (2003) Do physicians correctly estimate radiation risks from medical imaging? Arch Environ Health. 58:59-61

[21] Correia MJ, Hellies A, Andreassi MG, Ghelarducci B, Picano E (2005) Lack of radiological awareness among physicians working in a tertiary-care cardiological centre. International Journal of Cardiology 105: 307-311Soye J A, Paterson A; A Survey of Awareness of Radiation Dose among Health Professionals in Northern Ireland; British Journal of Radiology; (2008); 81; $525-527$.

[22] Soye J A, Paterson A; A Survey of Awareness of Radiation Dose among Health Professionals in Northern Ireland; British Journal of Radiology; (2008); 81; 525-527.

Table 1-Qualification distribution of respondents, TASH, November, 2009

\begin{tabular}{|l|r|r|r|r|}
\hline & Frequency & Percent & Valid Percent & $\begin{array}{c}\text { Cumulative } \\
\text { Percent }\end{array}$ \\
\hline Intern & 33 & 28.9 & 28.9 & 28.9 \\
GP & 2 & 1.8 & 1.8 & 30.7 \\
Resident & 61 & 53.5 & 53.5 & 84.2 \\
consultant & 18 & 15.8 & 15.8 & 100.0 \\
Total & 114 & 100.0 & 100.0 & \\
\hline
\end{tabular}

Table-2 Distribution of respondents by specialty, TASH, 2009.

\begin{tabular}{|l|r|r|r|}
\hline \multicolumn{1}{|c|}{ Specialty } & $\begin{array}{r}\text { Frequenc } \\
\text { y }\end{array}$ & Percent & $\begin{array}{c}\text { Cumulativ } \\
\text { e Percent }\end{array}$ \\
\hline Radiology & 12 & 10.5 & 9.7 \\
Internal & 15 & 13.15 & 24.3 \\
Medicine & 14 & 12.28 & 37.9 \\
Surgery & 10 & 8.7 & 47.6 \\
Gyn/Obs & 9 & 7.9 & 56.3 \\
Pediatrics & 1 & 0.9 & 58.3 \\
Orthopedics & 18 & 15.8 & 75.7 \\
Consultants & 35 & 30.7 & 100.0 \\
No Specialty & 114 & 100.0 & \\
Total & &
\end{tabular}


Table-3: Distribution of respondents to the radiation absorbed in a CXR, TASH, AA, November, 2009

\begin{tabular}{|c|r|r|r|}
\hline $\begin{array}{c}\text { Absorbed } \\
\text { dose (miliSeviert) }\end{array}$ & Frequency & Percent & $\begin{array}{c}\text { Cumulative } \\
\text { Percent }\end{array}$ \\
\hline $0.02 \mathrm{mSv}$ & 32 & 28.1 & 28.1 \\
$0.2 \mathrm{mSv}$ & 21 & 18.4 & 46.5 \\
$2 \mathrm{mSv}$ & 10 & 8.8 & 55.3 \\
$20 \mathrm{mSv}$ & 8 & 7.0 & 62.3 \\
don`t know & 43 & 37.7 & 100.0 \\
Total & 114 & 100.0 & \\
\hline
\end{tabular}

Table-4: Distribution of respondents in comparing effective dose of CXR from annual dose of background radiation in terms of absorbed dose. TASH, Addis Ababa, November, 2009.

\begin{tabular}{|c|r|r|r|}
\hline $\begin{array}{r}\text { Effective dose/ } \\
\text { annual dose }(\mathrm{mSv})\end{array}$ & Frequency & Percent & $\begin{array}{c}\text { Cumulative } \\
\text { Percent }\end{array}$ \\
\hline $1 / 100$ & 32 & 28.1 & 28.1 \\
$1 / 10$ & 22 & 19.3 & 47.4 \\
$10 \times$ & 13 & 11.4 & 58.8 \\
$100 \times$ & 9 & 7.9 & 66.7 \\
don`t know & 38 & 33.3 & 100.0 \\
Total & 114 & 100.0 & \\
& & & \\
\hline
\end{tabular}

Table-5: Distribution of respondents in assessing the relative risk of CXR (1 unit) Vs MRI of Brain (with contrast) TASH, Addis Ababa, November, 2009.

\begin{tabular}{|l|r|r|r|}
\hline Dose (unit) & Frequency & Percent & $\begin{array}{c}\text { Cumulative } \\
\text { Percent }\end{array}$ \\
\hline $0-1$ & 68 & 59.6 & 59.6 \\
$1-50$ & 5 & 4.4 & 64.0 \\
$50-100$ & 1 & .9 & 64.9 \\
$100-500$ & 2 & 1.8 & 66.7 \\
Don`t know & 38 & 33.3 & 100.0 \\
Total & 114 & 100.0 & \\
\hline
\end{tabular}

Table-6: Distribution of respondents in estimating lifetime cancer risk from an Abdominal CT with contrast TASH, Addis Ababa, November, 2009.

\begin{tabular}{|l|r|r|r|}
\hline Risk estimation (ratio) & Frequency & Percent & \multicolumn{2}{c|}{$\begin{array}{c}\text { Pumulative } \\
\text { Percent }\end{array}$} \\
\hline$<1$ in $1,000,000$ & 17 & 14.9 & 14.9 \\
1 in 300,000 to 1 in 10,000 & 37 & 32.5 & 47.4 \\
1 in 10,000 to 1 in 5000 & 12 & 10.5 & 57.9 \\
1 in 5000 to 1 in 1000 & 10 & 8.8 & 66.7 \\
don't know & 38 & 33.3 & 100.0 \\
Total & 114 & 100.0 & \\
\hline
\end{tabular}

